\title{
BMJ Open Macroeconomic costs of the unmet burden of surgical disease in Sierra Leone: a retrospective economic analysis
}

\author{
Caris E Grimes, ${ }^{1,2}$ Matthew Quaife, ${ }^{3}$ Thaim B Kamara, ${ }^{4,5}$ Christopher B D Lavy, ${ }^{6}$ \\ Andy J M Leather, ${ }^{1}$ Håkon A Bolkan ${ }^{7,8,9}$
}

To cite: Grimes $\mathrm{CE}$, Quaife M, Kamara TB, et al. Macroeconomic costs of the unmet burden of surgical disease in Sierra Leone: a retrospective economic analysis. BMJ Open 2018;8:e017824. doi:10.1136/ bmjopen-2017-017824

- Prepublication history and additional material for this paper are available online. To view these files, please visit the journal online (http://dx.doi. org/10.1136/bmjopen-2017017824).

Received 23 May 2017 Revised 31 August 2017 Accepted 24 January 2018

Check for updates

For numbered affiliations see end of article.

Correspondence to and Dr Caris E Grimes; carisgrimes@doctors.org.uk

\section{ABSTRACT}

Objectives The Lancet Commission on Global Surgery estimated that low/middle-income countries will lose an estimated cumulative loss of US\$12.3 trillion from gross domestic product (GDP) due to the unmet burden of surgical disease. However, no country-specific data currently exist. We aimed to estimate the costs to the Sierra Leone economy from death and disability which may have been averted by surgical care

Design We used estimates of total, met and unmet need from two main sources-a cluster randomised, cross-sectional, countrywide survey and a retrospective, nationwide study on surgery in Sierra Leone. We calculated estimated disability-adjusted life years from morbidity and mortality for the estimated unmet burden and modelled the likely economic impact using three different methods-gross national income per capita, lifetime earnings foregone and value of a statistical life. Results In 2012, estimated, discounted lifetime losses to the Sierra Leone economy from the unmet burden of surgical disease was between US\$1.1 and US\$3.8 billion, depending on the economic method used. These lifetime Iosses equate to between $23 \%$ and $100 \%$ of the annual GDP for Sierra Leone. 80\% of economic losses were due to mortality. The incremental losses averted by scale up of surgical provision to the Lancet Commission target of $80 \%$ were calculated to be between US\$360 million and US\$2.9 billion.

Conclusion There is a large economic loss from the unmet need for surgical care in Sierra Leone. There is an immediate need for massive investment to counteract ongoing economic losses.

\section{INTRODUCTION}

Although once described as the 'neglected stepchild of global health', ${ }^{1}$ surgery is increasingly being recognised as an indivisible, indispensable part of healthcare. ${ }^{2}$ Currently, surgical disease accounts for an estimated $33 \%$ of the global burden of disease, ${ }^{3}$ with an estimated 5 billion people have no access to safe, affordable surgical care and anaesthesia when needed $^{4}$ and an estimated 143 million additional procedures needed in low/middle-income countries (LMICs) to save lives and to prevent disability. ${ }^{5}$ Surgical access is weakest

\section{Strengths and limitations of this study}

The Lancet Commission on Global Surgery estimated cumulative losses from unmet surgical need of US $\$ 12.3$ trillion globally. This is the first countryspecific study to estimate macroeconomic losses.

- Estimates of unmet need in this study are based on previous studies. It is not possible to be certain exactly what the unmet surgical need is.

- Likewise, true death and disability averted is impossible to be accurately determined and is based on estimates.

- All modelling strategies have their limitations, especially in resource-poor settings. Therefore, we used three different approaches for comparison.

in low-income countries. ${ }^{6}$ Although traditionally thought of as an expensive intervention, cost-effectiveness analyses have shown that surgeries-both individual procedures and surgical platforms-are cost-effective when compared with other widely implemented health interventions. ${ }^{7}$

A number of studies have shown the profound economic impact on individuals and households resulting from untreated surgical conditions, with resulting death and disability. ${ }^{8}$ However, treatment of such conditions can improve the quality of life, household income as well as social status. ${ }^{10}$ Reducing deaths and disability from road traffic accidents alone in LMICs to the level of high-income countries would result in a potential economic saving of US\$758786 billion per year. ${ }^{11}$ If there is no accelerated urgent scale up of surgical services, LMICs are estimated to lose a cumulative US $\$ 12.3$ trillion to their economies over the next 15 years. ${ }^{5}$

To date, there have been no country-specific estimates of the economic costs resulting from loss of productivity due to death and disability from surgically treatable disease. Sierra Leone has been estimated to have a 
Table 1 Weightings definition

\begin{tabular}{lll}
\hline $\begin{array}{l}\text { Weighting } \\
\text { given }\end{array}$ & Risk of death or permanent disability & Treatment efficacy \\
\hline 0 & Condition fatal or permanently disabling $<5 \%$ of the time & $<5 \%$ chance of permanent cure \\
0.3 & Condition fatal or permanently disabling $5 \%-50 \%$ of the time & $5 \%-50 \%$ chance of permanent cure \\
0.7 & Condition fatal or permanently disabling $50 \%-95 \%$ of the time & $50 \%-95 \%$ chance of permanent cure \\
1 & Condition fatal or permanently disabling $>95 \%$ of the time & $>95 \%$ chance of permanent cure \\
\hline
\end{tabular}

high burden of surgical disease, with a household survey suggesting that $25 \%$ of deaths in the previous year may have been averted by timely surgical intervention, and $25 \%$ of respondents claiming to have a surgical condition requiring attention. ${ }^{12}$ Results from a national survey reported that there were 24152 operations in Sierra Leone in 2012 across all hospitals (government and private) amounting to a national average of 400 operations per 100000 . This amounts to approximately $8 \%$ of surgical disease treated and $92 \%$ untreated. Our aim was to estimate the likely impact on the Sierra Leonean gross domestic product (GDP) resulting from this untreated surgical disease.

This study is carried out in the context of slow improvements in health and economic indicators for Sierra Leone compared with other West African countries. Although life expectancy at birth increased from 41 to 51 years between 2002 and 2014, this remains the lowest life expectancy of any country assessed by WHO. ${ }^{13}$ Malnutrition, communicable diseases and poor maternal and child health services cause substantial mortality and morbidity each year. ${ }^{14}$ The country has a growing and youthful population driven by a high total fertility rate of almost five children per woman, yet a small and largely agrarian economy underuses this potential of its workforce with an estimated $60 \%$ youth unemployment attributable to poor educational outcomes, a lack of private sector jobs and low pay. ${ }^{15}$ Sierra Leone ranks 179 out of 188 countries included in the United Nations Development Programme's Human Development Index, a composite ranking of health, educational and economic outcomes by country. ${ }^{16}$

\section{METHODS}

\section{Disability-adjusted life year}

The disability-adjusted life year (DALY) is a composite measure of health quantity and quality which seeks to capture the negative consequences of premature mortality alongside burden from morbidity for the duration of an illness:

$$
\begin{gathered}
\text { DALYs }=\mathrm{YLD}+\mathrm{YLL} \\
\mathrm{YLD}=\mathrm{I} \times \mathrm{D} \times \mathrm{DW} \\
\mathrm{YLL}=\mathrm{N} \times \mathrm{LD}
\end{gathered}
$$

where YLD is the number of years lost due to disability, I the incidence of a condition, D the duration of illness, DW the disability weight, YLL the years of life lost, $\mathrm{N}$ the number of deaths from a condition and LD the life expectancy at age of death. DALYs are sometimes weighted differently according to the age at which a person dies in theory to reflect societal values around death at younger age. This is a controversial topic in the calculation of DALYs and, as in WHO Global Burden of Disease (GBD) studies since 2001, we do not apply age weighting in this analysis. We used local life expectancies from WHO's Life Table for Sierra Leone in $2012^{13}$ and disability weights published by the GBD Study. ${ }^{17}$

Details of all operations performed in Sierra Leone in 2012 from every surgical provider was obtained from a nationwide, retrospective study. ${ }^{18}$ Data were excluded if there was no recorded age for the patient or no recorded operation. The remaining records were then analysed. For each operation, we used a weighting system used by previous authors ${ }^{192}$ to determine the likely threat to life without treatment, the likelihood of permanent disability and the likely efficacy of treatment (table 1). Operations were deemed to either avert death or disability as in table 2. Weights for each operation were estimated using a Delphi method of local doctors and experts in each field. Operations were weighted differently depending on whether they were 'emergency' or 'planned' operations. Those where it was unclear whether it was performed as a planned or an emergency operation were weighted as for a 'planned' operation. Assumptions for each operation are shown in table 2. Disability weights for conditions primarily causing disability were obtained from the Global Burden of Disease Study. ${ }^{17}$

\section{Methods for calculating economic losses}

A number of methods are available to calculate economic losses due to preventable health conditions, and we opt to take three approaches which are simple and transparent in nature.

Acknowledging the breadth of literature in this area, we use three different approaches to estimate productivity losses from unmet surgery need: two applying the human capital approach (HCA), first using inputs of GDP/ capita and second lifetime earnings forgone, alongside a method incorporating the value of a statistical life.

Both HCA approaches use national accounts or workforce participation and earnings data and do not require extensive assumptions around the structure of the Sierra Leonean economy. These methods may therefore underestimate economic losses because they do not capture dynamic effects of reductions in morbidity or mortality, 
Table 2 Delphi weights for primarily death-averting and primarily disability-averting operations with assumptions on earnings

\begin{tabular}{|c|c|c|c|c|}
\hline & $\begin{array}{l}\text { Threat to } \\
\text { life }\end{array}$ & $\begin{array}{l}\text { Treatment } \\
\text { efficacy }\end{array}$ & $\begin{array}{l}\text { Risk of } \\
\text { permanent } \\
\text { disability }\end{array}$ & Assumption on earnings \\
\hline \multicolumn{5}{|l|}{ Primarily death averting } \\
\hline Appendectomy & 0.7 & 1.0 & & \\
\hline Caesarian section & 0.3 & 0.7 & & \\
\hline Cervical or vaginal laceration & 0.1 & 1.0 & & \\
\hline Dilatation and curettage & 0.3 & 0.7 & & \\
\hline Hernia repair (emergency) & 0.7 & 1.0 & & \\
\hline Hysterectomy & 0.3 & 0.7 & & \\
\hline Laparotomy-emergency & 1.0 & 0.7 & & \\
\hline Neonatal surgery (emergency) & 1.0 & 0.7 & & \\
\hline Repair of ruptured uterus & 1.0 & 1.0 & & \\
\hline Ectopic pregnancy & 0.7 & 1.0 & & \\
\hline Tracheostomy & 1.0 & 0.7 & & \\
\hline Amputation of limb & 1.0 & 0.7 & & \\
\hline \multicolumn{5}{|l|}{ Primarily disability averting } \\
\hline Cataract surgery & & 0.7 & 0.7 & $60 \%$ lifetime earnings lost \\
\hline Cleft lip repair & & 0.7 & 1.0 & No impact (no literature found) \\
\hline Cystostomy & & 1.0 & 0.7 & No impact (no literature found) \\
\hline
\end{tabular}

for example, the economic productivity from additional children of persons whose death is delayed by surgery. The methods are consistent with the growing consensus in health economic evaluation that the societal perspective should be considered where possible to give a more accurate reflection of true economic losses to society, outside of direct health expenditure. ${ }^{21}$

The value of a statistical life (VSL) is the amount of money a person or society is willing to spend to save one life and is commonly used by public bodies to value lives saved in cost-benefit analyses of health, transport or environmental projects. ${ }^{22}$ Data often come from the labour market, where individuals sometimes make decisions that involve a trade-off between financial rewards and an increased risk of premature mortality. Economists use this revealed preference for risk to calculate their VSL, reflecting the amount individuals are willing to pay to avert the risk of dying. For example, if a welder on an oil rig was willing to accept a pay cut of $£ 1000$ to work on land where the risk of death was 0.001 lower, their VSL would be $£ 1$ million $(£ 1000 / 0.001)$. VSL estimates are often larger than production-based measures of welfare losses (including the HCA) but fit better into welfare economic frameworks because they allow the worth of individuals to be greater than their wage rate.

We present economic losses both as an absolute number for income loss discounted to 2014 US\$ and as a percentage of GDP; however, we note caution in interpreting the latter. Household earnings (and subsequent consumption) are elements of GDP calculations, alongside aggregate government expenditure and business investment, among others. As elsewhere in the literature, ${ }^{23}$ we use the comparison between projected losses and actual GDP as a useful relative frame to understand the large numbers produced by this model. However, we emphasise that these are not directly causal and, in fact, may understate the direct effect of unmet surgery need on GDP. Finally, we compare figures to the 2014 GDP of Sierra Leone due to the anticipated negative impact of Ebola virus disease on the Sierra Leonean economy. ${ }^{24}$ 
Table 3 Total number of disability-adjusted life years averted by operation

No of operations in 2012

\begin{tabular}{|c|c|}
\hline \multicolumn{2}{|l|}{ Primarily death averting } \\
\hline Amputation & 234 \\
\hline Appendectomy & 1114 \\
\hline Caesarian section & 2646 \\
\hline Cervical or vaginal laceration & 24 \\
\hline Chest tube & 35 \\
\hline Dilatation and curettage & 508 \\
\hline Hernia repair (emergency) & 166 \\
\hline Hysterectomy (all) & 218 \\
\hline Laparotomy (all) & 815 \\
\hline Malignancy & 173 \\
\hline Manual placenta removal & 65 \\
\hline Necrosectomy & 1 \\
\hline Neonatal surgery (emergency) & 13 \\
\hline Manual placenta removal & 8 \\
\hline Salpingectomy for ectopic pregnancy & 10 \\
\hline Ectopic pregnancy & 103 \\
\hline Tracheostomy & 8 \\
\hline \multicolumn{2}{|l|}{ Primarily disability averting } \\
\hline Cataract surgery & 2242 \\
\hline Cleft lip repair & 2 \\
\hline Cystectomy & 16 \\
\hline Fracture & 964 \\
\hline Hernia repair (planned/unknown) & 3435 \\
\hline Neonatal surgery (planned/unknown) & 5 \\
\hline Obstetric fistula repair & 201 \\
\hline Urethral stricture dilation & 59 \\
\hline Total & 13065 \\
\hline
\end{tabular}

\section{Modelling approach}

The need for surgery in Sierra Leone was calculated from two cluster randomised, cross-sectional, countrywide surveys. ${ }^{125}$ First, we generate a counterfactual scenario where all annual mortality and disability is avoided by assuming current met need is $8 \%$, as estimated by Bolkan et $a l,{ }^{18}$ although this is likely to be a conservative estimate. Then, we present different scenarios of met need according to published studies and benchmarks, aggregating reductions in mortality and morbidity separately.

The literature has not reached consensus on how to estimate productivity losses due to morbidity. ${ }^{22}$ We take a pragmatic approach and obtain condition-specific data from the literature to estimate the proportion of persons with surgically treatable conditions who were unable to work following the development of a condition (table 2). Where no evidence of productivity effects are noted, we take a conservative approach and assume that untreated persons do not suffer productivity losses. Further information is provided in online supplementary file 1.

\section{ESTIMATION OF ECONOMIC LOSSES}

We use three methods to estimate economic losses:

\section{Gross national income per capita}

A common application of the HCA, recommended by the WHO Commission on Macroeconomics and Health, is to use gross national income (GNI) per capita to estimate the potential economic gains from gaining an additional year of life. ${ }^{26}$ This approach has been applied elsewhere to estimate economic gains and losses of health interventions. Although the GNI/capita approach may undervalue benefits from averting a DALY as it does not account for externalities on the wider labour market or care required from family members, the method is transparent and broadly accepted in the literature. ${ }^{22}$ Thus, GNI/capita approximates the economic value that the average individual adds to a society per year, and we simply multiply GNI/capita by the number of DALYs averted in each scenario of met surgical need.

\section{Lifetime earnings forgone}

The GNI/capita approach does not necessarily equate to the majority of individuals' economic productivity, particularly in unequal economies such as Sierra Leone, where few very productive individuals may bias mean earning estimates. Therefore, we calculate the present value of lifetime earnings (PVLE) forgone for each age category, slightly adapting the model presented in Menzin et $_{\text {al. }}{ }^{27}$

$$
\operatorname{PVLE}_{\text {paid }}(i, j, k)=\sum_{i=s_{j}}^{n_{j}} \frac{\left(l_{i, j, k} * w_{i, j, k}\right)}{(1+r)^{i-s_{j}}}
$$

where the estimated losses for a cohort of persons with age $i$, gender $j$, working in employment sector $k$ and with life expectancy $s_{j}$ are a weighted average of their economic activity, $l$, and wage rate $w$. We split each gender into five age groups, driven by the availability of data on avertable mortality and morbidity and use the midpoint of each strata to estimate years of productive life remaining.

We use data from the nationally representative 2011 Sierra Leone Integrated Household Survey (SLIHS) ${ }^{28}$ to obtain estimates of labour force participation by gender. We estimate the proportion of the population not in the labour force, the proportion employed in agriculture and the proportion in other waged industry. For both employed groups, we use SLIHS data to calculate the number of hours worked per year and apply earnings and salary data to estimate total annual earnings.

\section{Value of a statistical life}

A number of methods exist to calculate the VSL in Sierra Leone, which are briefly summarised in online supplementary table 1 . For our main analysis, we use $\$ 90700$ as calculated for sub-Saharan Africa by Robinson and Hammit. ${ }^{29}$ We follow Alkire $e t a l^{30}$ and convert this VSL 


\begin{tabular}{lcll} 
Table 4 & \multicolumn{2}{c}{ Summary of met surgical need in 2012} \\
\hline $\begin{array}{l}\text { Age } \\
\text { (years) }\end{array}$ & $\begin{array}{l}\text { Deaths } \\
\text { averted } \\
\text { in 2012 }\end{array}$ & $\begin{array}{l}\text { Mortality DALYs } \\
\text { averted due to } \\
\text { surgery in 2012 (YLL) }\end{array}$ & $\begin{array}{l}\text { Morbidity DALYs } \\
\text { averted due to } \\
\text { surgery in 2012 (YLD) }\end{array}$ \\
\hline $1-4$ & 58 & 1073 & 293 \\
\hline $5-15$ & 214 & 3877 & 741 \\
\hline $16-19$ & 278 & 4936 & 566 \\
\hline $20-33$ & 778 & 13086 & 2225 \\
\hline $34+$ & 332 & 5173 & 3626 \\
\hline
\end{tabular}

DALYs, disability-adjusted life years; YLD, years lost due to disability; YLL, years of life lost.

into its annualised equivalent, the value of a statistical life year, for use with DALYs. Here, we assume that the VSL is analogous to an annuity, giving a constant stream of income of $\$ 31415$ per year (5\% discount rate). Consistent with DALY calculations, we do not apply age weighting to this value so assume it remains constant throughout a lifetime. The use of Sierra Leonean data negates the rescaling of VSL from the USA, as elsewhere. ${ }^{29} 31$

\section{Discount rate}

The choice of discount rate can have a large impact on the results of an economic analysis, particularly when benefits or costs occur a long time after initial expenditure. ${ }^{32}$ We use a discount rate of $5 \%$ on costs and benefits. We explore the effect of higher discount rates in a sensitivity analysis.

\section{Uncertainty and sensitivity analyses}

We use a deterministic sensitivity analysis to explore methodological uncertainty stemming from the choice of discount rate, exploring a zero discount rate, $3 \%$ as per guidelines and $8.7 \%$ to mirror the local inflation rate. We carry out a multivariate probabilistic sensitivity analysis with 1000 Monte Carlo simulations of a number of variables simultaneously to assess the impact of parameter uncertainty on model predictions and present included parameters and distributional assumptions in online supplementary table 2.

\section{RESULTS}

\section{Met need in 2012}

Out of the 24152 operations recorded as being performed in Sierra Leone in 2012, 46\% were excluded-5672 because of a lack of detail about the operation and 5415 because there was no age recorded. We assumed that the $54 \%$ analysed were representative of the unmet need. Of the remaining operations, 6141 were death averting and 6924 were disability averting (table 3 ). Accounting for the probability of success in death-averting operations, 2219 deaths were averted through surgical intervention in 2012 (table 4).

\section{Health losses due to unmet need}

Assuming that the 24152 operations recorded in 2012 represent $7.9 \%$ of met surgical need in Sierra Leone, ${ }^{18}$ we estimate that unmet surgical need in 2012 resulted in 766606 DALYs forgone: 606981 DALYs lost due to mortality and 159625 due to morbidity. If surgical provision could be increased to $80 \%$ in line with the recommendations of the Lancet Commission on Global Surgery, an additional 599953 DALYs would be averted compared with 2012 provision. Reaching the goal of $50 \%$ provision would avert an additional 349972 DALYs, while the pragmatic target of $20 \%$ provision would result in 99992 additional DALYs averted.

\section{Economic losses}

Figure 1 presents estimated discounted economic losses from unmet surgery need. As anticipated, using different approaches to estimate losses, resulted in vastly different figures. The value of a statistical life approach gave the highest figure: current economic losses due to unmet surgery need were estimated to be $\$ 3.8$ billion (all monetary figures presented as 2012 US\$), equivalent to $107 \%$ of Sierra Leone's GDP in 2012. The GNI/capita approach put forward by the WHO Macroeconomic Commission gave the next highest figure of $\$ 1.4$ billion (42\% of 2012 GDP), while the lifetime earnings forgone method gave an estimate of $\$ 1.1$ billion ( $31 \%$ of 2012 GDP). Economic losses due to mortality contributed to around $80 \%$ of total economic loss from unmet need across all measures. Finally, table 5 presents the incremental losses that would be averted if surgical provision were to be scaled up to each of the three target scenarios.

\section{Sensitivity analyses}

Figure 2 displays results from a one-way sensitivity analysis, analysing the change in estimates of unmet need as model parameters are varied in isolation. Estimates are particularly sensitive to assumptions of current unmet need and whether the productivity estimates consider morbidity in addition to mortality. Assumptions of earnings do not make a substantive difference to estimates using the lifetime earnings forgone method.

Figure 3 displays the results of a probabilistic sensitivity analysis alongside base case estimates, while error bars illustrate the 25th and 75th quartiles of Monte Carlo model runs. When accounting for parameter uncertainty in the Probabilistic Sensitivity Analysis (PSA), the model still predicts substantial economic losses due to unmet surgical need. Of all probabilistic simulations, $38 \%$ of estimates were greater than the deterministic estimate. The variability of VSL simulation estimates is between $61 \%$ and $73 \%$ greater than that of human capital approaches.

\section{DISCUSSION}

In 2013, the Lancet Commission on Investing in Health argued that investing in healthcare in LMICs produced profound returns on investment of between 


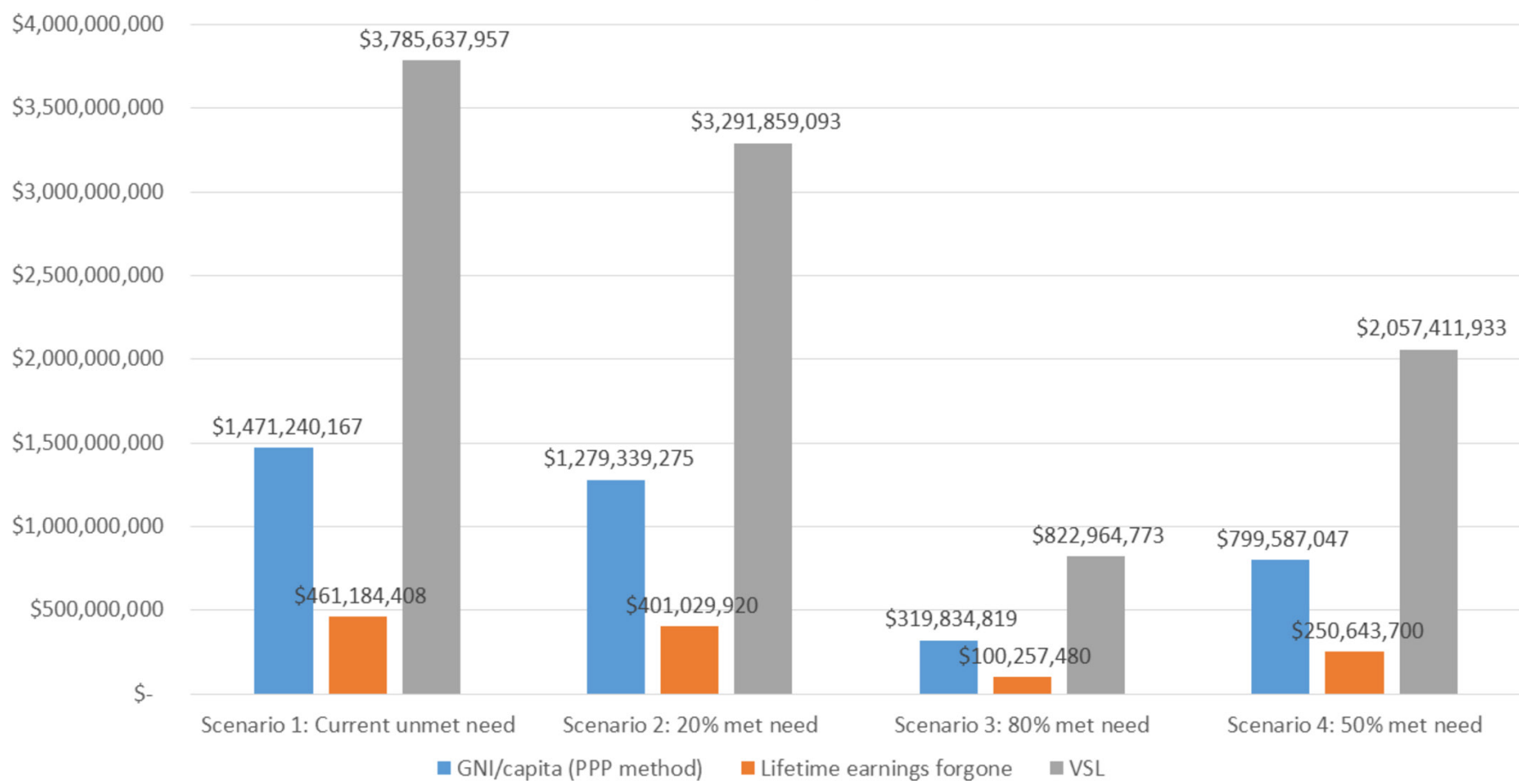

Figure 1 Estimated discounted lifetime economic losses due to unmet surgery need by scenario. GNI, gross national income; ppp, purchasing power parity; VSL, value of a statistical life.

US $\$ 9$ and US $\$ 20$ for every dollar invested. ${ }^{33}$ The question thus arose as to whether investment in the provision of surgical services to avert death and disability would give a similar financial return on investment. This question was addressed by the Lancet Commission on Global Surgery which presented data on both the economic impact of untreated disease and the financial commitment required to scale up surgical services. Alkire et al calculated projected economic losses in LMICs from a variety of surgical conditions using the value of lost output approach of up to $2.5 \%$ of annual GDP and $17 \%$ of 2010 GDP if a value of lost welfare approach was used. ${ }^{34}$ Verguet $e t a l^{35}$ modelled the possible scale up of surgical services in LMICs for the Lancet Commission on Global Surgery target of 5000 operations per 100000 population per year and calculated that costs of US\$300-420 billion would need to be met to achieve scale up over the years 2012-2030, representing 4\%-8\% of total annual health expenditure. This large investment in scaling up surgical services across 88 LMICs was positive when compared with the $\$ 12.3$ trillion loss to economic growth in these countries if surgical service development was neglected. The Lancet Commission on Global Surgery data presented a similar picture presented to the Lancet Commission on Investing in Health-investing in surgical care was beneficial and produced significant economic returns on investment.

The few studies that have been published on the macroeconomic impact of surgical disease in LMICs all show significant costs to national economies. ${ }^{11} 34$ This study demonstrates significant estimated costs to the economy of Sierra Leone from untreated surgical disease. It is the first single-country study and also represents a move away from modelled data to the use of primary surgical data for an estimation of the economic impact of untreated disease. The economic impact of untreated surgical disease in Sierra Leone is significant. In 2012, the estimated cumulative loss to the Sierra Leone economy from the unmet burden of surgical disease was between US $\$ 1.1$ and US $\$ 3.8$ billion, depending on the economic method used. This equates to between 23\% and $100 \%$ of the 2012 GDP for Sierra Leone. Eighty per cent of

Table 5 Incremental losses averted by scale up of surgical provision compared with current met need

\section{Incremental economic losses} averted

\section{GNI/capita (ppp)}

Earnings forgone (LYL only)

Value of a statistical life approach
Scenario 2: $20 \%$ met need Scenario 3: $80 \%$ met need Scenario 4: $50 \%$ met need

$\$ 191900891 \quad \$ 1151405348 \quad \$ 671653120$

$\$ 60154488 \quad \$ 360926928 \quad \$ 210540708$

$\$ 493778864$

GNI, gross national income; LYL, life years lost; PPP, purchasing power parity. 
One-way sensitivity analysis: Change in estimate of total economic losses at current met need

\section{$\$ 1,500,000,000$}

$\$ 1,000,000,000$

$\$ 500,000,000$

$\$-$

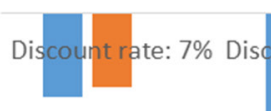

$\$-500,000,000$
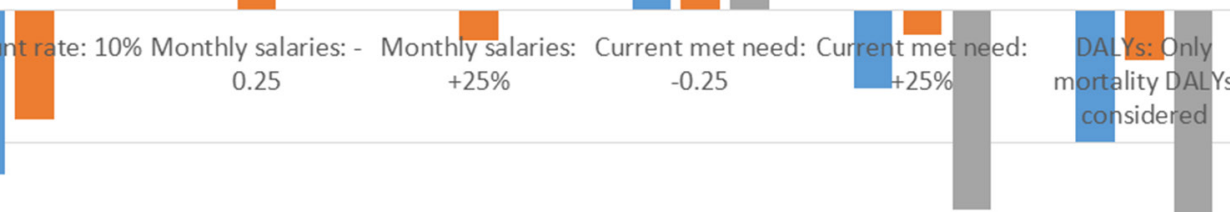

$\$-1,000,000,000$

$\$-1,500,000,000$

GNI/capita (PPP method) Lifetime earnings forgone VSL

Figure 2 One-way sensitivity analysis. DALYs, disability adjusted life years; GNI, gross national income; ppp, purchasing power parity; VSL, value of a statistical life.

economic losses were due to mortality. The incremental losses averted by scale up of surgical provision to the Lancet Commission target of $80 \%$ were calculated to be between US $\$ 360$ million and US $\$ 2.9$ billion, accepting that the Lancet Commission target was for $80 \%$ access to the Bellwether procedures, not for all surgery.

There are a number of limitations to this study. First, we had to discard $46 \%$ of the surgical data because they

Probabilistic Sensitivity Analysis Results

$\$ 7,000,000,000$

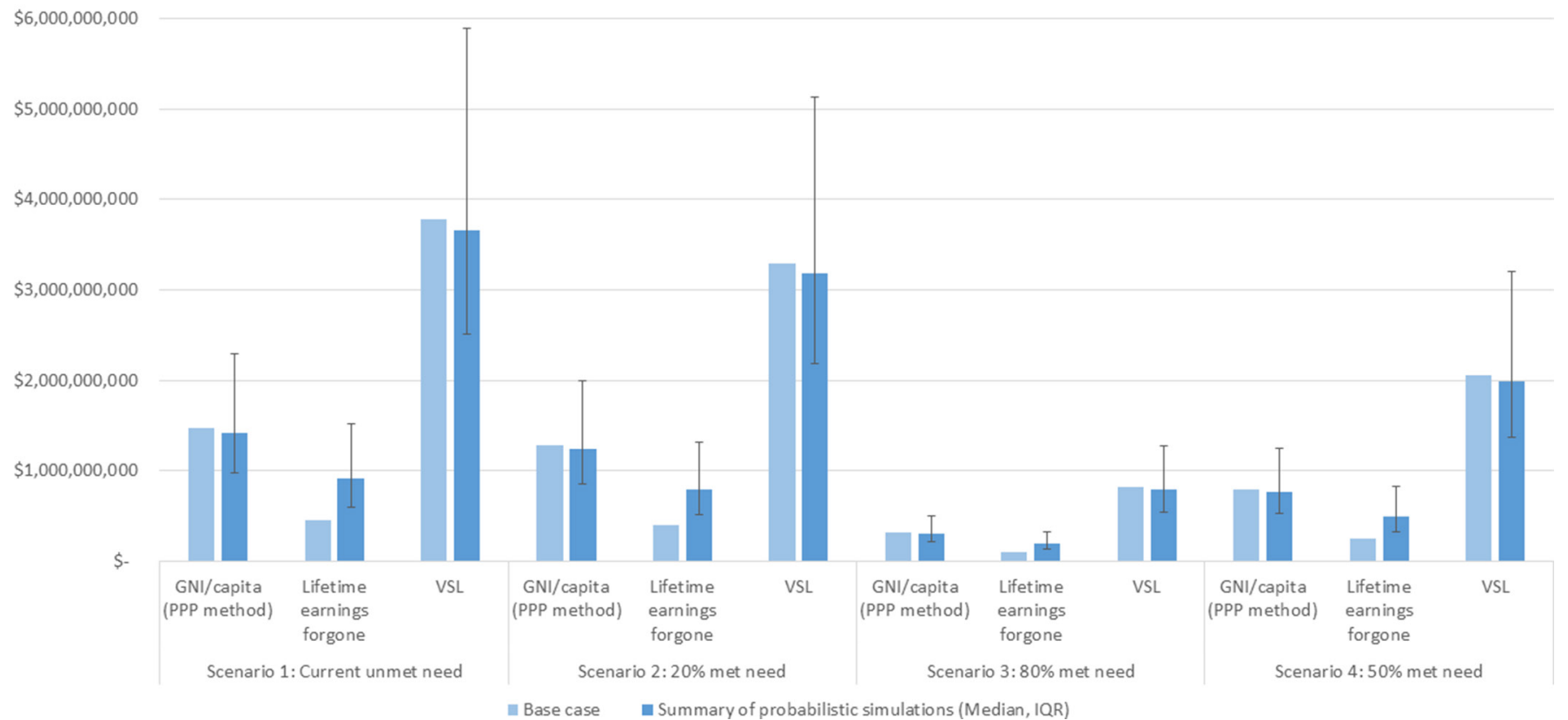

Figure 3 Probabilistic sensitivity analysis. GNI, gross national income; ppp, purchasing power parity; VSL, value of a statistical life. 
were incomplete. As a result, we worked with only $54 \%$ of the surgical data, which may not have been fully representative and may have skewed the results. We assumed that the $54 \%$ accounted for the $7.9 \%$ of met need and calculated unmet need based on this, although of course, if we had a full complement of data, the met need and hence the unmet need would have been significantly greater.

Where data were absent, for example when the age of patients was recorded but not their gender, we used complete data observations to weight how these were distributed across groups at the lowest level of aggregation available, for example, by age group. If observations were missing not at random (type 2 error), this could introduce bias into our estimates. We assumed operations not listed as either 'emergency' or 'planned' were planned, so as to create a conservative estimate of the overall economic impact. In practice, many of these may have been emergencies and would have made the resulting economic losses even greater. We assumed that the same proportion of met and unmet need was uniform across all operations. However, it may be that the proportion of met: unmet need may be higher for certain operations because of the nature of the pathology and the urgency for example, free healthcare for pregnant women might mean that the ratio of met: unmet need is higher for caesarean sections than it is for emergency laparotomy. We also assumed that treating a treatable condition would return the patient back to full economic productivity, although this may not be the case.

There is substantial variation between estimates of economic losses depending on the methodology used, despite all methods using an equivalent estimate of DALYs attributable to unmet need. The VSL method places the greatest value on each DALY incurred and by definition leads to the largest estimate of economic loss. The human capital approaches, using estimates of GNI/capita and lifetime earnings foregone, place a small cost on the loss of each DALY and produce smaller estimates. In addition, economic losses estimated here do not consider the value of unpaid or domestic work because of uncertainty in assumptions required and because these do not form part of many estimates of GDP. In addition, our use of financial measurements of economic productivity is a limitation in the largely agrarian economy of Sierra Leone. Other metrics, which cannot be easily valued in financial terms such as food insecurity or the distribution of labour within the household, may capture potentially important aspects of economic productivity. Omitting these factors makes our model more conservative and we are likely to underestimate total economic losses, with a greater underestimation occurring in female groups.

Averages (mean values) are used to parameterise the model, and we therefore do not account for heterogeneity in estimates except for between genders and the age at which surgery was required. Other literature has shown a notable correlation between propensity for ill health and income, particularly in low/middle-income contexts such as this study, and this model does not account for this. The lifetime earnings estimates in the human capital approach may overstate losses and therefore assume that premature mortality or morbidity causes a lifetime's impact to the economy. With more data, we could have used a friction cost method to be more conservative; however, the lost earnings estimates are the lowest produced in this study.

Despite these limitations which are prevalent in much of the global surgical literature, we have provided the first national study of economic losses based on as much data as is currently available for Sierra Leone. This suggests massive economic losses, much of which may be avertable by the provision of timely, surgical care. What is now required is the development of a costed national surgical plan as recently undertaken in Zambia. In the case of Sierra Leone, the necessary investment might be more than the Lancet Commission on Global Surgery figure of $4 \%-8 \%$ of total annual health expenditure as there is likely to be a large initial capital outlay as well as a very significant necessary investment in the surgical workforce. Only then will we be able to compare this required investment with our economic loss figures to quantify the return on surgical system investment in terms of lives saves and disability averted.

\section{Author affiliations}

${ }^{1}$ King's Centre for Global Health and Health Partnerships, King's College London and King's Health Partners, Weston Education Centre, London, UK

${ }^{2}$ Colorectal Surgery, Medway NHS Foundation Trust, Gillingham, United Kingdom ${ }^{3}$ Department of Global Health and Development, London School of Hygiene and Tropical Medicine, London, UK

${ }^{4}$ Department of Surgery, College of Medicine and Allied Health Sciences, Freetown, Sierra Leone

${ }^{5}$ Department of Surgery, Connaught Hospital, Freetown, Sierra Leone

${ }^{6}$ Department of Orthopaedics and Tropical Surgery, Oxford University, Oxford, UK ${ }^{7}$ Department of Cancer Research and Molecular Medicine, Norwegian University of Science and Technology (NTNU), Trondheim, Norway

${ }^{8}$ Department of Surgery, St Olav's Hospital, Trondheim, Norway

${ }^{9}$ CapaCare, Trondheim, Norway

Contributors CEG, AJML, CBDL and MQ contributed to the conception and design of the work. $\mathrm{HAB}$ and TBK contributed to the acquisition of the data. MQ and CEG analysed the data and wrote the initial draft of the manuscript. This was critically revised by AJML, CBDL, TBK and HAB. All have approved the final draft.

Funding CEG received a scholarship from the Sir Ratanji Dalal fund at the Royal College of Surgeons of England.

Competing interests None declared.

Patient consent Not required.

Provenance and peer review Not commissioned; externally peer reviewed.

Data sharing statement There is no available unpublished data from this particular study.

Open Access This is an Open Access article distributed in accordance with the Creative Commons Attribution Non Commercial (CC BY-NC 4.0) license, which permits others to distribute, remix, adapt, build upon this work non-commercially, and license their derivative works on different terms, provided the original work is properly cited and the use is non-commercial. See: http://creativecommons.org/ licenses/by-nc/4.0/

(c) Article author(s) (or their employer(s) unless otherwise stated in the text of the article) 2018. All rights reserved. No commercial use is permitted unless otherwise expressly granted. 


\section{REFERENCES}

1. Farmer PE, Kim JY. Surgery and global health: a view from beyond the OR. World J Surg 2008;32:533-6.

2. Kim JY. Opening address to the inaugural "The Lancet Commission on Global Surgery" meeting: The World Bank, 2014. http://www. globalsurgery.info/wp-content/uploads/2014/01/Jim-Kim-GlobalSurgery-Transcribed.pdf (accessed 28 Jan 2016).

3. Shrime MG, Bickler SW, Alkire BC, et al. Global burden of surgical disease: an estimation from the provider perspective. Lancet Glob Health 2015;3(Suppl 2):S8-9.

4. Alkire BC, Raykar NP, Shrime MG, et al. Global access to surgical care: a modelling study. Lancet Glob Health 2015;3:e316-e323.

5. Meara JG, Leather AJ, Hagander L, et al. Global Surgery 2030: evidence and solutions for achieving health, welfare, and economic development. Lancet 2015;386:569-624.

6. Weiser TG, Regenbogen SE, Thompson KD, et al. An estimation of the global volume of surgery: a modelling strategy based on available data. Lancet 2008;372:139-44.

7. Chao TE, Sharma K, Mandigo M, et al. Cost-effectiveness of surgery and its policy implications for global health: a systematic review and analysis. Lancet Glob Health 2014;2:e334-45.

8. El Tayeb S, Abdalla S, Heuch I, et al. Socioeconomic and disability consequences of injuries in the Sudan: a community-based survey in Khartoum State. Inj Prev 2015;21(e1):e56-62.

9. Dalal K, Lin Z, Gifford M, et al. Economics of global burden of road traffic injuries and their relationship with health system variables. Int $J$ Prev Med 2013;4:1442-50.

10. Finger RP, Kupitz DG, Fenwick E, et al. The impact of successful cataract surgery on quality of life, household income and social status in South India. PLoS One 2012;7:e44268.

11. Kotagal M, Agarwal-Harding KJ, Mock C, et al. Health and economic benefits of improved injury prevention and trauma care worldwide. PLoS One 2014;9:e91862.

12. Groen RS, Samai M, Stewart KA, et al. Untreated surgical conditions in Sierra Leone: a cluster randomised, cross-sectional, countrywide survey. Lancet 2012;380:1082-7.

13. WHO. Life Tables by Country. http://apps.who.int/gho/data/view. main.61480?lang=en (accessed 15 Jan 2016).

14. Institute for Health Metrics and Evaluation. Sierra Leone Country Metrics. 2017 http://www.healthdata.org/sierra-leone (accessed 15 Aug 2017).

15. United States Central Intellegence Agency. CIA World Factbook. Washington DC: United States Central Intellegence Agency, 2017. https://www.cia.gov/library/publications/download/index.html

16. United Nations Development Programme. Human Development Index and its components: United Nations Development Programme, 2016. http://hdr.undp.org/en/composite/HDI

17. Salomon JA, Vos T, Hogan DR, et al. Common values in assessing health outcomes from disease and injury: disability weights measurement study for the Global Burden of Disease Study 2010. Lancet 2012;380:2129-43.
18. Bolkan HA, Von Schreeb J, Samai MM, et al. Met and unmet needs for surgery in Sierra Leone: a comprehensive, retrospective, countrywide survey from all health care facilities performing operations in 2012. Surgery 2015;157:992-1001.

19. Gosselin RA, Heitto M. Cost-effectiveness of a district trauma hospital in Battambang, Cambodia. World J Surg 2008;32:2450-3.

20. Poenaru D, Pemberton J, Frankfurter C, et al. Quantifying the disability from congenital anomalies averted through pediatric surgery: a cross-sectional comparison of a pediatric surgical unit in Kenya and Canada. World J Surg 2015;39:2198-206.

21. Bill and Melinda Gates Foundation. Gates Reference Case, 2014.

22. The Office of the Australian Safety and Compensation Council. The Health of Nations: The Value of a Statistical Life, 2008.

23. Ortega-Ortega M, Oliva-Moreno J, Jiménez-Aguilera JD, et al. Productivity loss due to premature mortality caused by blood cancer: a study based on patients undergoing stem cell transplantation. Gac Sanit 2015;29:178-83.

24. Thomas MR, Smith G, Ferreira FH, et al; The economic impact of ebola on sub-Saharan Africa: updated estimates for 2015, 2015.

25. Petroze RT, Groen RS, Niyonkuru F, et al. Estimating operative disease prevalence in a low-income country: results of a nationwide population survey in Rwanda. Surgery 2013;153:457-64.

26. World Health Organisation. Report of the Commission on Macroeconomics and Health: Investing in health for economic development. Geneva: World Health Organization, 2001.

27. Menzin J, Marton JP, Menzin JA, et al. Lost productivity due to premature mortality in developed and emerging countries: an application to smoking cessation. BMC Med Res Methodol 2012;12:1.

28. Statistics Sierra Leone (SSL). Sierra Leone-Integrated Household Survey 2011, 2011

29. Robinson LA, Hammitt JK. The value of reducing air pollution risks in sub-Saharan Africa. Lisa A Robinson 2009:5.

30. Alkire B, Hughes CD, Nash K, et al. Potential economic benefit of cleft lip and palate repair in sub-Saharan Africa. World J Surg 2011;35:1194-201.

31. Viscusi WK, Aldy JE. The value of a statistical life: a critical review of market estimates throughout the world. J Risk Uncertain 2003;27:5-76.

32. Jit M, Mibei W. Discounting in the evaluation of the costeffectiveness of a vaccination programme: a critical review. Vaccine 2015;33:3788-94.

33. Jamison DT, Summers LH, Alleyne G, et al. Global health 2035: a world converging within a generation. Lancet 2013;382:1898-955.

34. Alkire BC, Shrime MG, Dare AJ, et al. Global economic consequences of selected surgical diseases: a modelling study. Lancet Glob Health 2015;3(Suppl 2):S21-7.

35. Verguet S, Alkire BC, Bickler SW, et al. Timing and cost of scaling up surgical services in low-income and middle-income countries from 2012 to 2030: a modelling study. Lancet Glob Health 2015;3(Suppl 2):S28-37. 